\title{
The Nature of Unusual Luminescence in Natural Calcite $\mathrm{CaCO}_{3}$
}

\author{
Michael Gaft ${ }^{1, *}$, Lev Nagli ${ }^{2}$, Gerard Panczer ${ }^{3}$, Glenn Waychunas ${ }^{4}$ and Naomi Porat ${ }^{5}$ \\ ${ }^{1}$ Department of Natural Science, The Open University of Israel, Raanana, Israel \\ ${ }^{2}$ School of Physics and Astronomy, Tel-Aviv University, Tel-Aviv, Israel \\ ${ }^{3}$ Physical Chemistry of Luminescence Materials Laboratory, Lyon 1 University, \\ UMR 5620 CNRS, Villeurbanne, France \\ ${ }^{4}$ Geochemistry Dept., Earth Sciences Division, MS 70R108 E.O. Lawrence Berkeley \\ National Laboratory, Berkeley, CA 94720, U.S.A. \\ ${ }^{5}$ Geological Survey of Israel, Jerusalem, Israel
}

\begin{abstract}
* Present address: Laser Detect Systems, 11 Granit St, Petach Tikva, Israel. E-mail: michaelg@laserdetect.com
\end{abstract}

\begin{abstract}
.
The unusual luminescence of particular varieties of natural pink calcite $\left(\mathrm{CaCO}_{3}\right)$ samples was studied by laser-induced time-resolved luminescence spectroscopy at different temperatures. The luminescence is characterized by intense blue emission under short-wave UV lamp excitation with an extremely long decay time, accompanied by pink-orange luminescence under long wave UV excitation. Our investigation included optical absorption, natural thermostimulated luminescence (NTL) and Laser-Induced Breakdown Spectroscopy (LIBS) studies. Two luminescence centers were detected: a narrow violet band, with $\lambda_{\max }=412 \mathrm{~nm}, \Delta=45$ $\mathrm{nm}$, two decay components of $\tau_{1}=5 \mathrm{~ns}$ and $\tau_{2}=7.2 \mathrm{~ms}$, accompanied by very long afterglow, and an orange emission band with $\lambda_{\max }=595 \mathrm{~nm}, \Delta=90 \mathrm{~nm}$ and $\tau=5 \mathrm{~ns}$. Both luminescence centers are thermally unstable with the blue emission disappearing after heating at $500 \mathrm{C}$, and the orange emission disappearing after heating at different temperatures starting from $230^{\circ} \mathrm{C}$, although sometimes it is stable up to $500 \mathrm{C}$ in different samples. Both centers have spectral-kinetic properties very unusual for mineral luminescence, which in combination with extremely low impurity concentrations, prevent their identification with specific impurity related emission. The most likely explanation of these observations may be the presence of radiation-
\end{abstract}


induced luminescence centers. The long violet afterglow is evidently connected with trapped charge carrier liberation, with their subsequent migration through the valence band and ultimate recombination with a radiation-induced center responsible for the unusual violet luminescence.

Keywords

Calcite, time-resolved luminescence, radiation-induced luminescence centers

\section{Introduction}

Calcite is calcium carbonate, $\mathrm{CaCO}_{3}$, with a rhombohedral cell consisting of planar $\mathrm{CO}_{3}$ anion groups, and containing a $\mathrm{Ca}$ ion at the center of an equilateral triangle of oxygen atoms (symmetry $-32 / \mathrm{m}$ ). The structure of calcite is analogous to that of $\mathrm{NaCl}$ if we consider the unit cube of halite to be shortened along one trigonal axis.

Calcite is a well-studied luminescent mineral, where the following luminescence centers have been found and interpreted: $\mathrm{Mn}^{2+}, \mathrm{Pb}^{2+}, \mathrm{Ce}^{3+},\left(\mathrm{UO}_{2}\right)^{2+}, \mathrm{Dy}^{3+}, \mathrm{Sm}^{3+}, \mathrm{Tb}^{3+}$, $\mathrm{Tm}^{3+}, \mathrm{Nd}^{3+}, \mathrm{Eu}^{3+}$ and a radiation-induced center of violet emission (Gorobets and Rogojine 2001, Gaft et al. 2005).

One specific variety of calcite is known as Terlingua-type (TT) because of its original discovery in large quantities at Terlingua, Texas, an old Hg-mining area. It is characterized by unique intense blue emission under short-wave UV lamp excitation with an extremely long decay time, accompanied by pink-orange luminescence under long wave UV excitation. In both cases the emission is especially strong in the more physically colored parts, which may be pinkish to red, and rarely green. The purpose of this work is a detailed investigation of the spectral and kinetic parameters of this calcite luminescence in order to interpret its origin. Analyses of the spectral-kinetic properties of major emission bands in the broad temperature range 40-300 $\mathrm{K}$ were conducted. Laser-induced time-resolved spectroscopy was the principal tool, allowing discrimination between centers with emission in the same spectral range, but with different decay times. The method involves recording the intensity in a specific time gate at a given delay after the excitation pulse. Such manipulation allows us to record separately the emissions corresponding to different decay times, and avoid the overlapping of emission produced from different centers. 
Experimental techniques

\section{Luminescence and UV-Visible Spectroscopy}

The time-resolved luminescence spectra were investigated using excimer $\mathrm{KrF}$ (248 $\mathrm{nm})$, nitrogen $(337 \mathrm{~nm})$ and $2^{\text {nd }}, 3^{\text {rd }}$ and $4^{\text {th }}$ Nd-YAG harmonics $(532,355$ and 266 $\mathrm{nm}$, respectively) pulsed lasers excitations, each pulse having 8-10 ns duration and 0.1 $\mathrm{cm}^{-1}$ spectral width. The spectra were observed at $90^{\circ}$ to the excitation beam direction and were analyzed by iStar equipment enabling time-resolving spectra acquisition with the following features: delay times and strobe pulse duration from $1 \mathrm{~ns}$ to $19 \mathrm{~ms}$, spectral detection range of 200 to $900 \mathrm{~nm}$, spectral resolution $0.5-1 \mathrm{~nm}$ (using gratings with 300 or 600 lines $/ \mathrm{mm}$, respectively), and use of an intensified CCD detector. Spectra were collected in 1200 channel arrays. A Pulsed Optical Parametric Oscillator (OPO) was also used as an excitation source, specifically for excitation spectrum determination in the visible range close to the orange luminescence band.

For Laser-Induced Breakdown Spectroscopy (LIBS) a focusing lens was added between the laser and the mineral sample to create enough power to form a plasma. The first harmonic of a Nd-YAG laser (1064 nm) was used for this plasma creation.

Steady-state luminescence and excitation spectra were studied under low-pressure $\mathrm{Hg}$-arc and $\mathrm{He} \mathrm{UV}$ lamps excitations, respectively. In the luminescence decay investigation pulsed lasers were used as the excitation source, while the sample luminescence was analyzed with the grating monochromator. A digital oscilloscope was used to process the output from the photomultiplier. The iStar equipment enables luminescence decay time measurements using a kinetic series regime [explain please**]. Luminescence spectra and decay times were measured at temperatures from 40 to $300 \mathrm{~K}$.

For optical measurements natural unpolished calcite samples were used. The optical absorption spectra in the spectral range from 190 to $1100 \mathrm{~nm}$ were recorded using a Jasco spectrophotometer (model V-530). All absorption spectra are unpolarized and recorded at $300 \mathrm{~K}$.

For Thermally Stimulated Luminescence (TL) studies the calcite pieces were measured on $\mathrm{Al}$ discs in a Risø DA-12 TL/OSL reader equipped with a bi-alkali photomultiplier. We studied only natural TL (NTL) unlike artificially induced TL, where samples are artificially irradiated before TL measurements. Thus all measured TL signals are the result of natural irradiation. The violet emission was detected 
through a filter combination of Schott BG-39, 7-59 and GG-400 glasses. A ${ }^{90} \mathrm{Sr}$ beta source was used to irradiate the samples after NTL measurements, to test whether the color lost on NTL is recovered by irradiation.

\section{Samples}

The specific calcites used with unusual luminescence properties originated from Boquillas Del Carmen, Coahuila, Mexico, but are representative of TT calcites found at Terlingua, Texas (USA), Deming, New Mexico (USA) and other localities. Large quantities of this calcite are available from Boquillas, hence it was used for the extensive studies presented here. Calcite with similar luminescence properties has been found in at least a dozen localities in the USA, and may be very common.

Impurities suspected as potential luminescence centers were analyzed by ICP-MS (Table 1). A red calcite sample without the specific TT luminescence was also analyzed for the sake of comparison. Data were evaluated by the certified Geological Service of Israel laboratory.

Rare-earth element (REE) measurement was done via neutron activation (Table 2) for a set of TT samples from several localities. Both pink and white areas from the same calcite samples were analyzed. Data were supplied by the Gemological Institute of America (GIA) through a vendor used for neutron activation analysis of gemstones.). Also tested were National Institute for Standards and Technology (NIST) standard REE materials (NBS278 and NBS1633A). All such standard analyses were found to be within standard errors of NIST chemical concentration measurements.

\section{Experimental results}

Optical absorption

The calcite samples are characterized by two main colorations, namely white (or colorless) and pink. Figures $1(\mathrm{a}, \mathrm{b})$ represent optical absorption spectra for the two varieties from the same specimen. Optical absorption spectra at $23 \mathrm{~K}$ from a cleavage face polarized in the direction of maximum pink color for a sample of TT calcite (Fig. 1c, Rossman (Internet site) and from colorless calcite without luminescence (Fig. 1d) are presented for comparison. 
An absorption spectrum of pink TT calcite differs from white calcite regions in the same samples and from colorless calcite by the presence of UV absorption bands peaking at 240, 290 and $370 \mathrm{~nm}$ and bands in the visible region peaking at 535 and $760 \mathrm{~nm}$. The optical absorption spectrum of our calcite in the visible range is very similar to those presented by Rossman (Caltech mineral spectroscopy internet site) while in the UV it resembles the absorption spectrum described by Bershov et al (1968) and Sergeev et al. (1976) for pink calcite from Kazakhstan. After heating the pink sample up to $\sim 175 \mathrm{C}$ the color becomes weaker, and after $200 \mathrm{C}$ it disappears, and the calcite becomes colorless. Subsequent X-ray and beta irradiations of this calcite sample did not restore the color.

\section{Laser-Induced Breakdown Spectroscopy (LIBS)}

A LIBS study revealed mainly $\mathrm{Ca}$ emission lines for both pink and white varieties. The main observation was that the ratio of intensity between the ionized calcium atoms $\mathrm{Ca}(\mathrm{II})$ (emission lines at 315.9 and $317.9 \mathrm{~nm}$ ) and the neutral $\mathrm{Ca}(\mathrm{I})$ atoms (emission lines at 334.9 and $336.1 \mathrm{~nm}$ ) detected from the laser-induced plasma was notably different as a function of coloration (Fig. 2). The $\mathrm{Ca}(\mathrm{II}) / \mathrm{Ca}$ (I) ratio in pink calcite (a) is substantially lower than that found for white calcite (d), but changes as result of heating and approaches that for white calcite $(b, c)$. Such behavior is the same for all other emission lines of $\mathrm{Ca}(\mathrm{II})$ and $\mathrm{Ca}(\mathrm{I})$ throughout the UV-Visible spectral range.

Time-resolved luminescence spectroscopy

\section{A. Violet emission band}

During continuous illumination of these calcite samples under short wave UV (257 $\mathrm{nm}$ ) the emission color starts pink, and then quickly becomes blue. It actually intensifies over several seconds with continuous short wave UV excitation.

Under laser excitations at 248, 266, 337 and $355 \mathrm{~nm}$, and at $300 \mathrm{~K}$, TT calcite has an intense UV to violet emission band peaking at $412 \mathrm{~nm}$ with a half-width of $\sim 55$ $\mathrm{nm}$ (Fig. 3a). The excitation spectrum of this band is composed of a short-wave tail in the spectral range less than $250 \mathrm{~nm}$, and two UV bands peaking at 295 and $365 \mathrm{~nm}$ (Fig. 3b). The band intensity is much stronger in the pink calcite samples. The decay 
function contains two components, a very short one with $\tau_{1}=5 \mathrm{~ns}$ and a very long one with $\tau_{2}=7.1 \mathrm{~ms}$ (Figs. 3c, d). The total similarity of the violet luminescence spectra and its decay components under different excitations indicates that we are dealing with one luminescence center with two decay components and not with two different luminescence centers.

At temperatures lower than $300 \mathrm{~K}$ the emission spectrum changes drastically. With decreasing temperature to $200 \mathrm{~K}$, it has the same general form, but emission intensity is constantly lower (Fig. 4a, b). A second band at $470 \mathrm{~nm}$ appears and dominates the spectrum at low temperatures (Fig. 4c, d). The intensity and maximum of this band is nearly the same from $120 \mathrm{~K}$ to $40 \mathrm{~K}$. However substantial changes are observed with in the decay times. The main decay component of the band peaking at $412 \mathrm{~nm}$ in the ms range becomes longer with decreasing temperature, reaching $\tau_{2}=20 \mathrm{~ms}$ at $265 \mathrm{~K}$ (Fig. 5a). The decay dependence of the band peaking at $472 \mathrm{~nm}$ is characterized by a prominent ns component starting from its appearance at approximately $220 \mathrm{~K}$ and down to $77 \mathrm{~K}$ (Fig. 5b). At still lower temperatures the luminescence spectrum, decay time and intensity remain approximately the same down to $4.2 \mathrm{~K}$.

After sample heating to $230{ }^{\circ} \mathrm{C}$ the violet band remains unchanged in energy, but its intensity weakens. It may be clearly seen only after a delay of $1 \mu \mathrm{s}$, while other emission bands with very short decay times disappear (Fig. 6a). Additional luminescence bands, are detectable only after the violet emission is considerably weakened. For example, $\mathrm{Ce}^{3+}$ (Blasse and Aguilar 1984) and $\mathrm{Pb}^{2+}$ (Gaft et al. 2002 (Fig. 6b, c) bands are observed. After heating at $600 \mathrm{C}$ the band at $412 \mathrm{~nm}$ entirely disappears, while another UV band at $402 \mathrm{~nm}$ appears (Fig. 6d).

\section{B. Orange emission band}

Under long wavelength UV (366 nm) and visible excitations a band peaking at 594 $\mathrm{nm}$ is observed with a half-width of $\sim 95 \mathrm{~nm}$ (Fig. 7a). The excitation spectrum of this emission contains four maxima peaking at 350, 370, 435 and $480 \mathrm{~nm}$ (Fig. 7b). The OPO tunable source enabled excitation at energies very close to the luminescence band. This revealed a prominent excitation band at $532 \mathrm{~nm}$, and thus a very small Stokes shift of 50-60 nm between the excitation and emission maxima (Fig. 7c). [explain here significance of small Stokes shift—e.g. crystal field, etc] 
The luminescence band is not symmetrical, with a shoulder at $625 \mathrm{~nm}$, but this feature remains in all time-resolved spectra with different delays and gates and does not resolve to separate emission bands. This band can be detected with an extremely narrow gate width, which is strong evidence that its decay time is very short, approximately 7-8 ns (Fig. 7d). This orange luminescence is especially strong in the most strongly colored parts of calcite (dark pink to red). At $40 \mathrm{~K}$ the band becomes very intense, while its spectrum and decay time remain practically the same.

The orange band is thermally unstable, but in different samples it disappears after heating to different temperatures in a wide range from 230 to $500{ }^{\circ} \mathrm{C}$. After this band disappears, another orange band becomes visible at $612 \mathrm{~nm}$ with a very long decay time of 8-10 ms. This band is consistent with a substitutional $\mathrm{Mn}^{2+}$ luminescence center (Tarashchan 1978, Gaft et al. 2005).

\section{Discussion of experimental results}

Violet luminescence band

For interpretation of the violet band at $412 \mathrm{~nm}$ it is important to determine if the blue band peaking at $470 \mathrm{~nm}$, and appearing only at low temperatures, is associated with the same luminescence center as the violet band, or if it is connected with an independent luminescence center. The $412 \mathrm{~nm}$ band is more prominent undershortwave UV excitation than under long-wave UV excitation. Figure 8 demonstrates that the intensity ratios for the 472 and $412 \mathrm{~nm}$ bands at $300 \mathrm{~K}$ and $77 \mathrm{~K}$ with excitation of $337 \mathrm{~nm}$ are different from excitation by $355 \mathrm{~nm}$, namely because the intensity of the blue band at $77 \mathrm{~K}$ is higher compared to the intensity of the violet band at $300 \mathrm{~K}$ under excitation of $337 \mathrm{~nm}$, while the ratio is opposite under $355 \mathrm{~nm}$ excitation. Thus, it may be concluded that these bands at 472 and $412 \mathrm{~nm}$ have different excitation spectra and must therefore belong to different luminescence centers.

Summarizing, the relatively narrow band with half-width of $45 \mathrm{~nm}$ peaking at 412 $\mathrm{nm}$ at room temperature, has two decay components, one in the ns range and the second in the ms range. With decreasing temperature its spectral form remains constant, while the intensity decreases. The decay component in the ms range becomes longer with decreasing temperature. Such luminescence properties may be explained by a configurational diagram scheme with one ground state and two very 
closely spaced excited states, where the radiative transition from the lowest excited state to the ground state is totally forbidden, while from the higher excited state to the groud state it is totally allowed. In such case, excited electrons exist in both lowest and higher excited states with $\mathrm{n}_{1}$ (lower) and $\mathrm{n}_{\mathrm{h}}$ (higher) populations. At low temperatures $n_{l}$ evidently is substantially higher than $n_{h}$, and luminescence intensity is low with a very short lifetime due to the few $\mathrm{n}_{\mathrm{h}}$ electrons. With increased temperature, the higher excited state is more populated and the luminescence intensity is stronger with two decay components, one very short from the original $n_{h}$ electrons and another very long due to electrons arriving from $n_{1}$.

A violet emission band having two decay components, such as described in this paper, is very unusual for mineral luminescence. Traditional luminescence centers for minerals in this spectral range, such as $\mathrm{Ce}^{3+}$, and $\mathrm{Eu}^{2+}$, cannot explain it. Emission of $\mathrm{Ce}^{3+}$ in calcite is characterized by a rather broad UV luminescence band with two emission maxima and only one short decay lifetime component of 20 ns (Gorobets and Rogojine 2001, Gaft et al. 2005). Europium concentrations in our calcite samples are extremely low (Table 2) and Eu decay behavior is usually characterized by one decay component of 600-800 ns (Gaft et al. 2005). Thus direct connection between an Eu center and the violet luminescence band in our calcite specimens is very doubtful.

Two types of luminescence centers have suitable energy levels schemes to explain the violet band spectral kinetics: $\mathrm{s}^{2}$ type elements such as $\mathrm{Tl}^{+}, \mathrm{Pb}^{2+}, \mathrm{Bi}^{3+}, \mathrm{Sn}^{2+}$ and $\mathrm{Sb}^{3+}$ (Blasse and Grabmaier 1994) and radiation induced F- centers Parfianovich and Penzina 1977). The $\mathrm{s}^{2}$ ions have a ${ }^{1} \mathrm{~S}_{0}$ ground state. The excited sp state gives a triplet ${ }^{3} \mathrm{P}_{0,1,2}$ for spins parallel, and a singlet ${ }^{1} \mathrm{P}_{1}$ for spins antiparallel. In view of the selection rules, only transitions between the singlet states are allowed. For the heavy $6 s^{2}$ ions, such as $\mathrm{Bi}^{3+}$, the transitions between the ground state and the ${ }^{3} \mathrm{P}_{1}$ state are intensified due to significant spin-orbit mixing of the ${ }^{3} \mathrm{P}_{1}$ and ${ }^{1} \mathrm{P}_{1}$ states. After excitation at low temperature, the system relaxes to the lowest excited state, but ${ }^{3} \mathrm{P}_{1}$ and ${ }^{3} \mathrm{P}_{0}$ are close enough in energy such that at higher temperatures luminescence from the ${ }^{3} \mathrm{P}_{1}$ level may appear. Nevertheless, according to the ICP-MS analyses, the concentrations of elements capable of forming such the luminescence centersare very low in our samples (Table 1), and definitely are not the distinctive chemical feature. Hence it may be concluded that the violet luminescence band is not connected with a typical impurity center. 
The other possibility is a radiation-induced luminescence center. The best-known radiation-induced center is the F-center. It consists of an electron in a halide vacancy, for example in $\mathrm{KCl}$. A good approximation of its absorption spectrum are the electronic states of the hydrogen atom [ref needed here]. An F-center has a ground state of s-type and a split excited level, where the lower excited state is mainly of stype and electron transitions to the ground state are forbidden, while the higher state is mainly of p-type and electron transitions to the ground state are allowed. We have no geological evidence for the possible irradiation events leading to the formation of such radiation-induced centers in our calcite sample, but several indirect indications are present.

\section{A. Pink color}

The nature of pink coloration in calcite has been intensively studied and two possible models have been proposed. In Kazakhstan samples an elevated concentration of $\mathrm{Pb}$ was detected, from 0.1 to $2 \%$. This color is thermally unstable and disappears after heating at $300 \mathrm{C}$ together with all absorption bands except one at $240 \mathrm{~nm}$, which has been assigned to $\mathrm{Pb}^{2+}$ absorption [ref ?]. The thermally bleached calcite has its pink color restored after X-ray, gamma ray or electron irradiation. The pink color has been ascribed to absorption bands at 370 and $500 \mathrm{~nm}$ connected with $\mathrm{Ca}^{2+}$ vacancies and $\mathrm{CO}_{3}{ }^{2-}$ units, respectively, which form as a result of ionizing irradiation. Usually such centers are not stable at room temperature, but it has been postulated that they can be stabilized by some kind of structural defects, such as $\mathrm{Pb}^{2+}$ substituting for $\mathrm{Ca}^{2+}$ (Bershov et al. 1968, Sergeev et al. 1973, 1976). We studied a Kazakhstan calcite sample with pink color and high $\mathrm{Pb}$ concentration (Table 1) for comparison, but unusual luminescence was not detected.

On the other hand, we did not find an elevated concentration of $\mathrm{Pb}$ in any pink calcite samples having the with unique TT luminescence (Table 1). The luminescence band at $312 \mathrm{~nm}$ (Fig. 5) can be assigned to a $\mathrm{Pb}^{2+}$ luminescence center, but laserinduced luminescence is much more efficient than UV absorption-excited emission. In addition, the pink coloration in our samples is different from the Kazakhstan samples. vIt disappears after heating at $\sim 200 \mathrm{C}$ and not $300 \mathrm{C}$, and it is not restored after X-ray or beta irradiation. Thus it may be concluded that the pink color in our calcite is not connected with a $\mathrm{Pb}^{2+}$ impurity. 
The data in Table 2 demonstrate that many TT pink calcites samples are definitely enriched by rare-earth elements compared to the white or colorless areas in the same samples by a factor of 2 to 30, depending on the element. Thus our analytical data correspond with Rossman's interpretation, where the pink color is assigned to radiation damage centers, which often involve rare earths ( Caltech mineral spectroscopy internet site).

The luminescence of the violet band is much greater in the colored parts of the calcite compared to the colorless areas. It is well known that the sensitivity of luminescence spectroscopy is much greater than optical absorption spectroscopy, thus if any radiation-induced centers produce the pink calcite coloration, their concentration is definitely enough to generate luminescence activity.

\section{B. Natural thermostimulated luminescence (NTL)}

Other evidence for natural irradiation is the presence of NTL in the pink calcite samples. Figure 9(a) shows that the NTL signal detected through violet-blue filters, corresponding to the violet-blue calcite emission spectrum, is very strong. Several peaks at 227, 263, 335, 412 and $460 \mathrm{C}$ characterize it, although the first two peaks are sometimes absent. Kazakhstan samples also have NTL, but the spectra are different from our TT calcite results. In the Kazakhstan samples the most prominent peak is situated at $133 \mathrm{C}$, while two weaker bands are present at 210 and $323 \mathrm{C}$. The energy depths of corresponding traps have been calculated as $0.95 \mathrm{eV}$ for the TL peak at 133 ${ }^{\circ} \mathrm{C}$, and $1.83 \mathrm{eV}$ for the TL peak at $323^{\circ} \mathrm{C}$. It has been calculated that at $30^{\circ} \mathrm{C}$ the traps responsible for the first TL peak would be emptied after 800 years (Sergeev et al. 1976), which may be the reason for their absence in our TT samples. It is important to note that unusual violet luminescence or phosphorescence have never been mentioned for the Kazakhstan pink calcite samples [more refs here for these samples?]. Further, such a band is absent in thermally stimulated emission spectra measured for different TL peaks. For temperatures below $133^{\circ} \mathrm{C}$ the main emission bands are at $320 \mathrm{~nm}$, evidently connected with $\mathrm{Pb}^{2+}$, and a very broad band peaking at $450 \mathrm{~nm}$ of unknown nature. At temperatures higher than $300 \mathrm{C}$ these emission bands are absent. On the other hand, different types of violet afterglow were detected in our samples (Fig. 9b) as a result of isothermal TL in all NTL maxima up to $400 \mathrm{C}$. It may be seen that a long rise time is typical for several glow curves, especially at $335^{\circ} \mathrm{C}$, which explains the fact that the violet emission increases in intensity for a few seconds with 
continued short wave UV excitation. It is important to note that all of our NTL studies were accomplished using a narrow range violet filter so that all other possible emission bands could not contribute to our signals.

The strong afterglow of the violet emission, which can still be observed for several seconds after the end of the excitation pulse, must be due to the trapping of electrons or holes. Figure 10 is a schematic illustration of a possible model for this process. As a result of natural ionizing irradiation, calcite contains both luminescence centers and also trapping centers. After UV excitation, intrinsic emission inside the violet luminescence center takes place as described above, with two decay components in the ns and ms ranges. In concert with this, light with energy larger than that needed to transfer the electrons from the traps to the conduction band yields free electrons and holes. One possibility is that the holes are trapped by the luminescent centers, whereas the electrons in the conduction band recombine with the holes, yielding emission. Another possibility is that a fraction of the electrons is trapped in the electron trap centers, from where they escape thermally or optically after some delay. Only then will they recombine with trapped holes, with recombination energy exciting the luminescence center. Hence, the corresponding emission occurs with considerable delay.

\section{Laser-induced breakdown spectroscopy (LIBS)}

It is well known that some differences exist in the characteristics of the laserinduced plasma depending on the hardness of the sample. For example, for elements having a low ionization potential, such as $\mathrm{Ca}$, the ionic emission intensity (CaII) from a hard stone is far stronger than the $\mathrm{Ca}$ neutral (CaI) emission intensity, while for a soft sample ionization occurs weakly because the speed of the shock wave would be slowed down due to the lack of a repulsive force on the sample surface, resulting in a reduction in the ionic emission intensity. Such analysis has been used for estimation of concrete compressive strength (Tsuyuki et al. 2006). According to such an approach, the very low relative intensity of ionic $\mathrm{Ca}$ (II) in pink areas of a calcite sample may be due to its relative softness compared to the white areas. One possible reason may be metamictization of the calcite as result of irradiation accompanying by elevated water content inside the calcite structure. Such an interpretation is consistent with the relative increase of ionic $\mathrm{Ca}(\mathrm{II})$ intensity observed as a result of pink calcite heating. After heating at $500 \mathrm{C}$, probably accompanied by water loss and 
recrystallization, though these aspects were not measured, the $\mathrm{Ca}(\mathrm{II}) / \mathrm{Ca}(\mathrm{I})$ ratios of originally pink calcite becomes similar to those for the white regions (Fig. 2). This hypothesis is consistent with the idea that the pink calcite was subjected to strong natural irradiation, but it is speculative and requires further confirmation, such as from microhardness, IR and Raman measurements.

Hence it may be concluded that the violet luminescence is not connected with a simple impurity center. It seems most likely to be associated with a radiation induced defect center. However the violet luminescence is not connected directly with the radiation-induced pink color center, because their thermal stability is quite different. After heating a pink sample up to $\sim 230 \mathrm{C}$ the pink color disappears and the calcite becomes colorless, while the violet emission band remains unchanged up to much higher temperatures. It also was found that the violet luminescence disappears after $\mathrm{X}$-ray excitation, which may be interpreted as an indication that it is a hole center. The reason is that usually after X-ray irradiation the holes are localized very quickly, while the electrons have enough time to reach luminescence centers associated with holes and annihilate them as result of electron-hole recombination (Parfianovich and Penzina 1977). Nevertheless, the exact nature of the violet luminescence center is likely to be determined only by correlation with extensive EPR measurements.

\section{Orange luminescence band}

The orange emission band with decay time of several ns is very unusual, because as a rule broad orange-red luminescence bands in minerals have decay times from several $\mu \mathrm{s}\left(\mathrm{Ti}^{3+}, \mathrm{Bi}^{2+}, \mathrm{Cr}^{3+}\right)$ to several $\mathrm{ms}\left(\mathrm{Mn}^{2+}, \mathrm{Fe}^{3+}, \mathrm{Cr}^{3+}\right)$ (Gaft et al. 2005). It is interesting to note that the orange band peaking near $600 \mathrm{~nm}$ was detected in the thermally stimulated emission of Kazakhstan pink calcite, but without measurement of the decay time it was originally ascribed to a substitutional $\mathrm{Mn}^{2+}$ luminescence center (Sergeev et al. 1976). A possible exception from the usual connection of the orange emission in minerals with $\mathrm{Mn}^{2+}$ centers is the orange luminescence in rosecolored elbaite peaking at $570 \mathrm{~nm}$, with emission intensity much stronger at lower temperatures (Tarashchan 1978). The decay time of such luminescence was not reported, but an allowed $2 \mathrm{p}->1$ s electron transition in color centers may have a lifetime in the ns range. The rose color of elbaite is thermally unstable and disappears after thermal treatment along with the orange luminescence. 
However, the thermal influence on the pink color and orange luminescence in TT calcite is different from elbaite. The color always disappears after heating at $230 \mathrm{C}$, while the orange luminescence is sometimes stable up to $500 \mathrm{C}$. In addition, X-ray irradiation of heated calcite samples does not restore the color and luminescence. Thus we must conclude again that the orange luminescence center in the TT calcites is probably due to a radiation-induced origin. The radiation source must be different from X-rays, which is a case similar to that for zircon luminescence, where X-ray irradiation does not restore the yellow luminescence after heating, while alphaparticles and neutron irradiation do (Gaft et al. 2005). We expect that the exact nature of this luminescence center can only be clarified by correlation of EPR measurements on TT samples and other appropriate standard materials.

Acknowledgments

The authors are grateful for The Open University of Israel Research Department for providing the means for ICP-MS analyses. We also thank the Gemological Institute of America (GIA) for assistance with the neutron activation analyses, and several preliminary investigations on TT calcite samples, and GIA scientists Emmanual Fritsch and James Shigley for helpful discussions. GAW's work is partially supported by the U.S. Department of Energy under Contract No. DE-AC02-05CH11231.

\section{References}

Bershov, L., Samoylovich, M., Lushnikov, V., and Andrusenko, N. (1968) Nature of pink color in calcite (in Russian). Zapiski Vsesoyuznogo Mineralogicheskogo Obshchestva (ZVMO), 97, 357-360.

Blasse, G. and Aguilar, M. (1984) Luminescence of natural calcite $\left(\mathrm{CaCO}_{3}\right)$. J of Luminescence, 29, 239-241.

Blasse, G. and Grabmaier, B. (1994) Luminescent materials, 198 p. Springer, Berlin Heidelberg New York.

Gaft, M., Seigel, H., Panczer, G., and Reisfeld, R. (2002) Laser-induced time-resolved luminescence of lead $\mathrm{Pb}^{2+}$ in Franklin, NJ, minerals. European J. of Mineralogy, 14, 1041-1048.

Gaft, M., Reisfeld, R., and Panczer, G. (2005) Modern luminescence spectroscopy of minerals and materials, 356 p. Springer, Berlin. 
Gorobets, B. and Rogojine, A. (2001) Luminescent spectra of minerals. Handbook, 215 p. RPC VIMS, Moscow.

Parfianovich, I. and Penzina, E. (1977) Electronic color centers in ion crystals, 250 p. Irkutsk (in Russian).

Rossman, G. http://minerals.gps.caltech.edu/

Sergeev, V., Barsanov, G., and Kononov, O. (1973) The nature of pink color in calcite. Vestnik MGU, Seriya Geologicheskaya, 2, 2115-2117 (in Russian).

Sergeev, V., Schukin, N., and Barsanov, G. (1976) Thermoluminescence of calcite with gold-pink color. DAN SSSR, 226, 6, 1407-1410 (in Russian).

Tarashchan, A. (1978) Luminescence of Minerals, 534 p. Naukova Dumka, Kiev (in Russian).

Tsuyuki, K., Miura, S., Idris, N., Kurniawan, K., Lie, T., and Kagawa, K. (2006)

Measurement of concrete strength using the emission intensity ratio between $\mathrm{Ca}$ (II)

$396.8 \mathrm{~nm}$ and $\mathrm{Ca}(\mathrm{I}) 422.6 \mathrm{~nm}$ in a Nd-YAG laser-induced plasma. Applied

Spectroscopy, 60/1, 61-64.

\section{Figure captions}

Figure 1. Optical absorption spectra of Terlingua-type calcites with different colors (a, b, d-our data, c-from reference [4]).

Figure 2. Laser-Induced Breakdown Spectra of natural pink calcite (a), pink calcite after thermal treatment $(b, c)$ and white calcite $(d)\left(\lambda_{e x}=1064 \mathrm{~nm}\right)$.

Figure 3. Luminescence spectrum (a), excitation spectrum (c) and decay time curves in ns range (b) and ms range (d) of violet luminescence band.

Figure 4. Luminescence spectra of violet emission bands at different temperatures $\left(\lambda_{\mathrm{ex}}=355 \mathrm{~nm}\right)$.

Figure 5. Decay times of violet emission bands at different temperatures $\left(\lambda_{\mathrm{ex}}=355\right.$ $\mathrm{nm})$.

Figure 6. Luminescence spectra of calcite after heating at 230 (a-c) and $600{ }^{\circ} \mathrm{C}$

Figure 7. Orange luminescence (a, c), excitation (b) and luminescence after heating at $230{ }^{\circ} \mathrm{C}(\mathrm{d})$ spectra 
[aren't there curves missing from this figure??] [where is the violet band in $\mathrm{b}$ and $\mathrm{c}$ ?]

Figure 8. Luminescence spectra in violet-blue range at 300 and $77 \mathrm{~K}$ under $337 \mathrm{~nm}$ (a) and $355 \mathrm{~nm}(\mathrm{~b}, \mathrm{c})$ excitations

Figure 9. Natural thermoluminescence (a) of several samples of pink calcite and isothermal decay (b) at different temperatures.

Figure 10. Luminescence center and different traps in energy gap of calcite (see text for explanation)

In my figures some of the axis labels are displaced. This may be due to difference in our vesions of WORD.

Table 1. Concentrations of impurities in pink and white calcites capable to form luminescence centers (ppm) determined by ICP-MS technique. Standard deviations (2 $\sigma)$ in parentheses.

\begin{tabular}{|l|l|l|l|}
\hline Impurity & White & Pink & Red \\
\hline Mn & $\mathbf{7 0 ( 4 )}$ & $45(2)$ & $110(5)$ \\
\hline Co & $<0.1$ & $<0.1$ & $<0.1$ \\
\hline Ni & $<0.5$ & $<0.5$ & $3.0(0.6)$ \\
\hline Cu & $<0.1$ & $<0.1$ & $<0.1$ \\
\hline Bi & $\mathbf{0 . 0 6 0 ( 0 . 0 1 2 )}$ & $0.020(0.004)$ & $0.041(0.008)$ \\
\hline Pb & $\mathbf{0 . 0 7 ( 0 . 0 1 )}$ & $0.03(0.01)$ & $18(1)$ \\
\hline Tl & $<0.01$ & $<0.01$ & $<0.01$ \\
\hline Sn & $<0.05$ & $<0.05$ & $<0.05$ \\
\hline Sb & $<0.01$ & $<0.01$ & $<0.01$ \\
\hline Ag & $<0.01$ & $<0.01$ & $0.04(0.01)$ \\
\hline U & $1.3(0.1)$ & $1.5(0.1)$ & $0.30(0.03)$ \\
\hline
\end{tabular}

Table 2. Concentrations of REE with luminescence properties in pink and white calcites (ppm) determined by NAA technique. Standard deviations $(2 \sigma)$ in parentheses.

\begin{tabular}{|l|l|l|l|l|l|l|l|l|}
\hline REE & $\begin{array}{l}\text { Sample 1 } \\
\text { Deming } \\
\text { NM } \\
\text { colorless }\end{array}$ & $\begin{array}{l}\text { Sample 2 } \\
\text { Hope IN } \\
\text { pink } \\
\text { color }\end{array}$ & $\begin{array}{l}\text { Sample 3 } \\
\text { Hope IN } \\
\text { Colorless }\end{array}$ & $\begin{array}{l}\text { Sample 4 } \\
\text { Coahulia } \\
\text { Mexico } \\
\text { colorless }\end{array}$ & $\begin{array}{l}\text { Sample 5 } \\
\text { Muncie } \\
\text { PA } \\
\text { pink color }\end{array}$ & $\begin{array}{l}\text { Sample 6 } \\
\text { Muncie } \\
\text { PA } \\
\text { colorless }\end{array}$ & $\begin{array}{l}\text { Sample 7 } \\
\text { Terlingua } \\
\text { TX } \\
\text { red-pink }\end{array}$ & $\begin{array}{l}\text { Sample 8 } \\
\text { Terlingua TX } \\
\text { Light pink- } \\
\text { colorless }\end{array}$ \\
\hline Tm & $\mathbf{. 0 3 2 ( . 0 3 3 )}$ & $\mathbf{. 0 2 2 ( . 0 2 3 )}$ & $\mathbf{. 0 4 0 ( . 0 4 1 )}$ & $\mathbf{. 0 3 5 ( . 0 3 6 )}$ & $\mathbf{2 . 2 5 ( . 5 1 9 )}$ & $\mathbf{. 1 1 0 ( . 0 2 9 )}$ & $\mathbf{. 0 2 1 ( . 0 2 2 )}$ & $\mathbf{. 0 2 5 ( . 0 0 7 )}$ \\
\hline Ce & $\mathbf{3 . 2 7 ( . 0 4 8 )}$ & $\mathbf{. 5 5 6 ( . 0 1 2 )}$ & $\mathbf{. 0 3 0 ( . 0 1 5 )}$ & $\mathbf{. 2 3 7 ( . 0 2 2 )}$ & $\mathbf{5 . 4 7 3 ( . 3 8 4 )}$ & $\mathbf{0 . 1 5 5 ( . 0 3 2 )}$ & $\mathbf{0 . 2 1 0 ( . 0 1 8 )}$ & $\mathbf{0 . 1 5 1 ( . 0 1 6 )}$ \\
\hline Yb & $\mathbf{. 4 1 8 ( . 0 3 3 )}$ & $\mathbf{. 0 6 0 ( . 0 0 7 )}$ & $\mathbf{. 0 2 2 ( . 0 1 0 )}$ & $\mathbf{. 0 8 2 ( . 0 1 5 )}$ & $\mathbf{. 5 1 3 ( . 5 1 5 )}$ & $\mathbf{. 0 1 8 ( . 0 1 8 )}$ & $\mathbf{. 0 8 4 ( . 0 1 2 )}$ & $\mathbf{. 0 4 9 ( . 0 1 0 )}$ \\
\hline
\end{tabular}




\begin{tabular}{|l|l|l|l|l|l|l|l|l|}
\hline & & & & & & & \\
\hline Tb & $.076(.004)$ & $.014(.001)$ & $.003(.002)$ & $.018(.002)$ & $.053(.029)$ & $.004(.004)$ & $.019(.001)$ & $.016(.001)$ \\
\hline Eu & $.111(.003)$ & $.025(.001)$ & $.005(.001)$ & $.022(.002)$ & $.077(.026)$ & $.007(.003)$ & $.032(.001)$ & $.022(.001)$ \\
\hline Ho & $.007(.001)$ & $.006(.001)$ & $.000(.0006)$ & $.012(.001)$ & $.002(.001)$ & $.054(.010)$ & $.004(.0007)$ & $.003(.0006)$ \\
\hline Sm & $.318(.001)$ & $.075(.0006)$ & $.000(.0008)$ & $.079(.0008)$ & $.023(.0006)$ & $.339(.004)$ & $.070(.0007)$ & $.040(.0005)$ \\
\hline
\end{tabular}
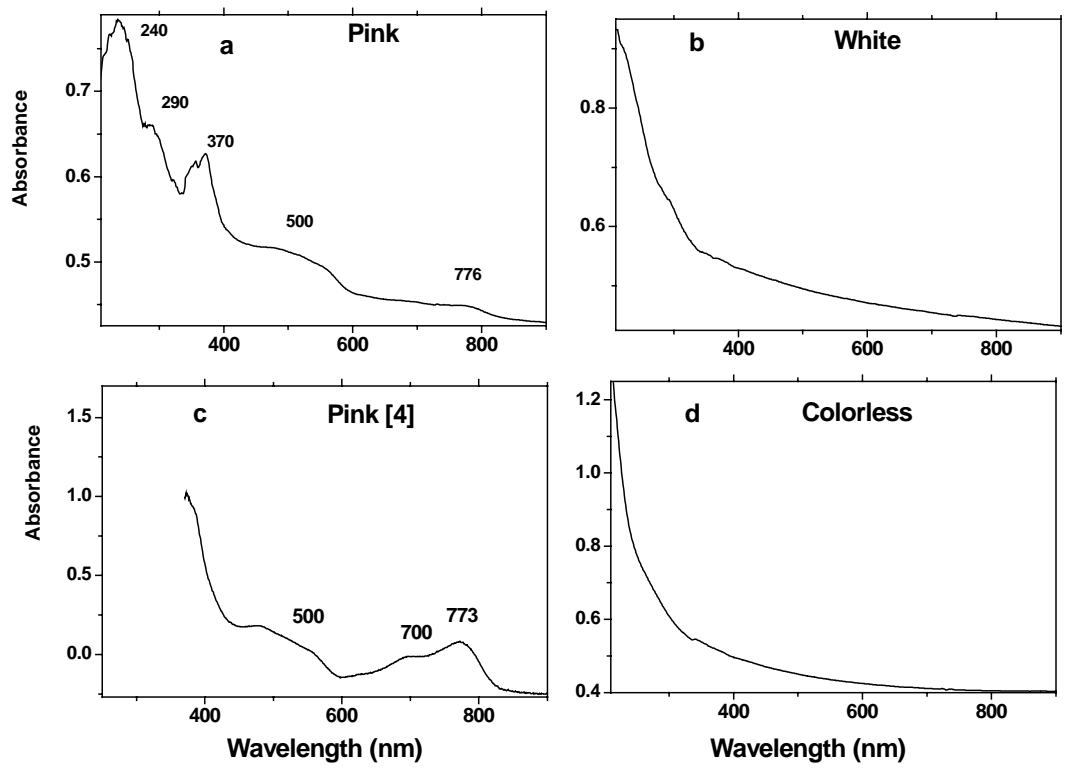

Figure 1. 

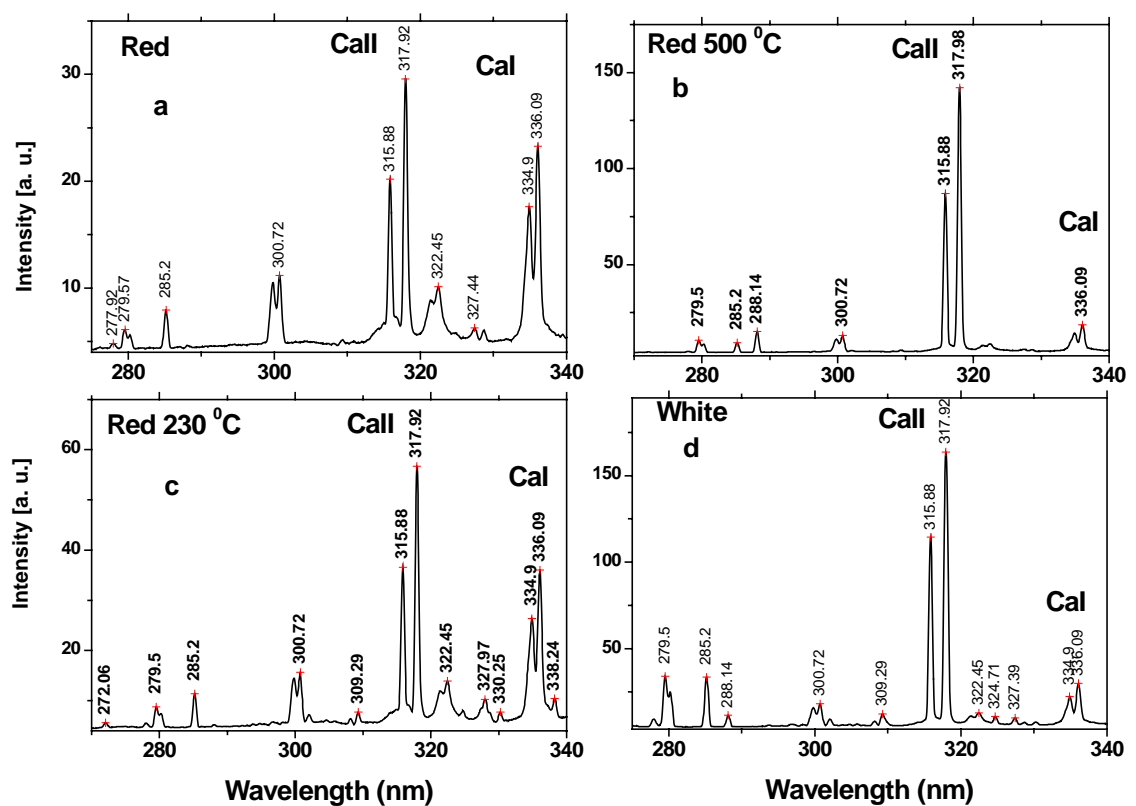

Figure 2.
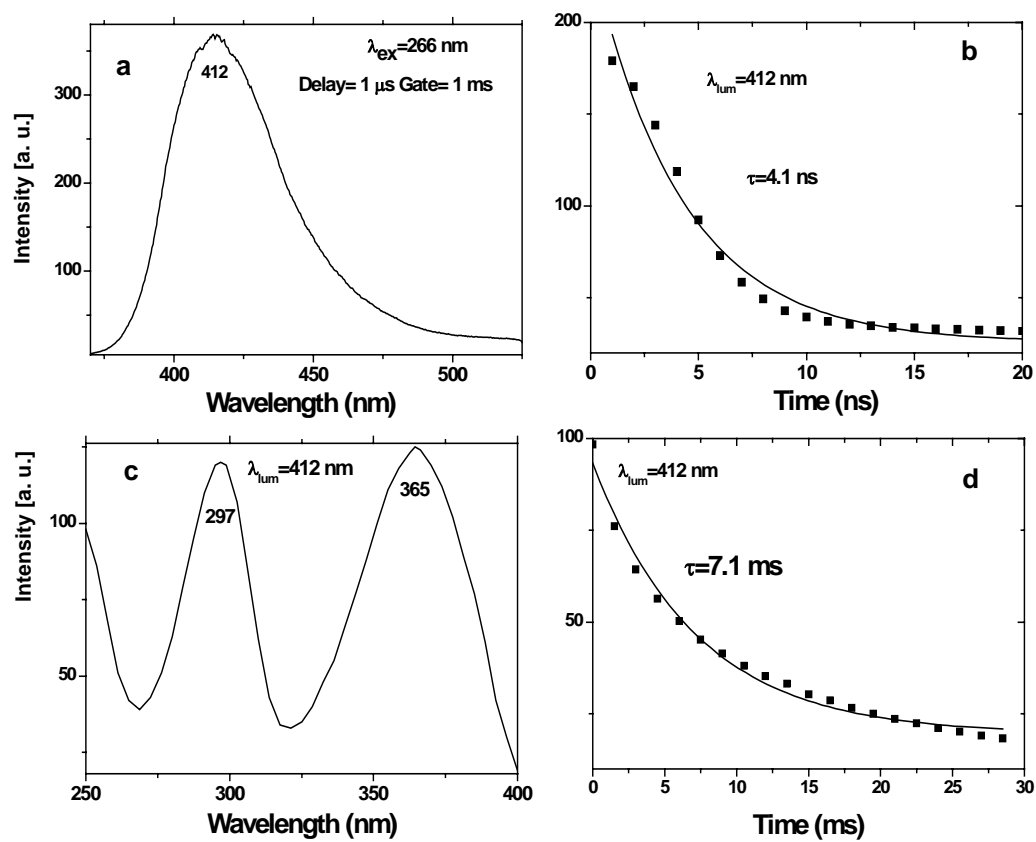

Figure 3. 

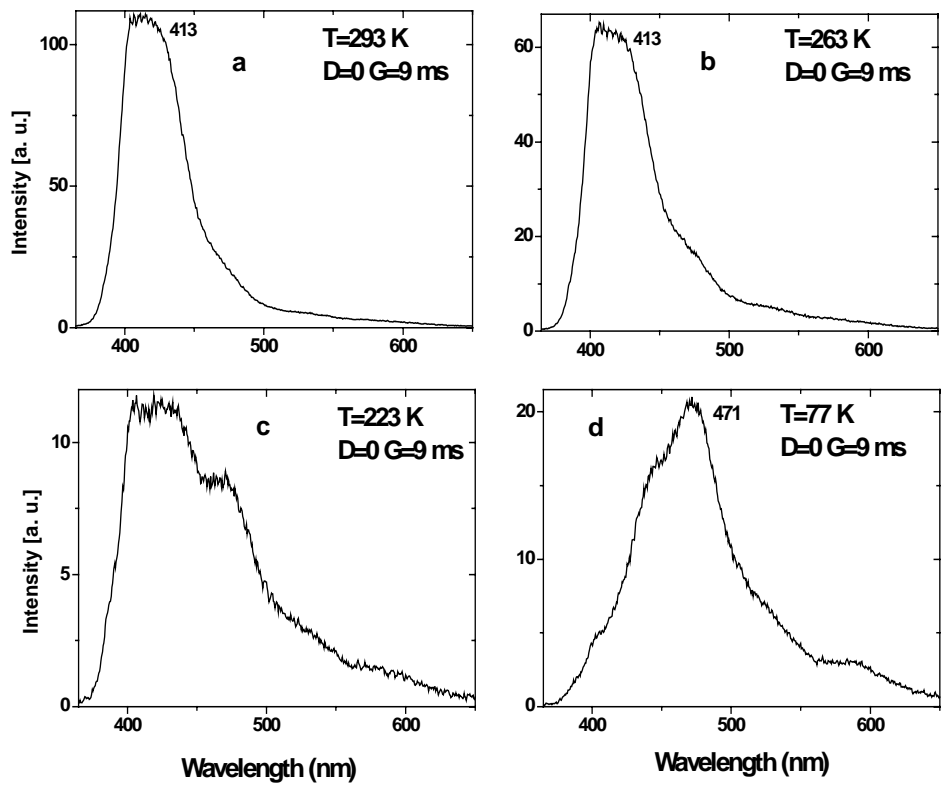

Figure 4.
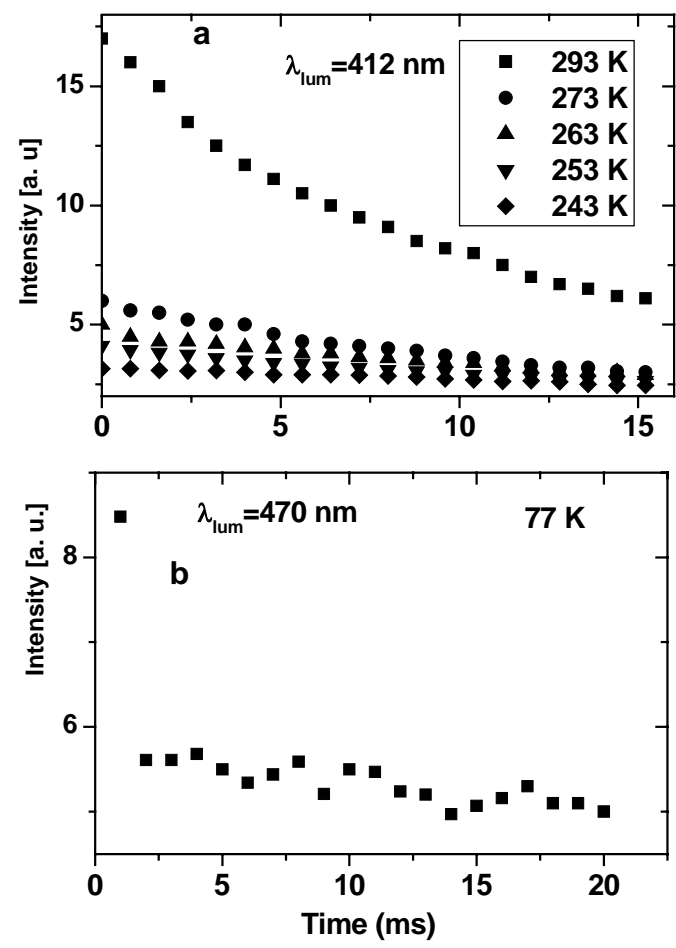

Figure 5. 

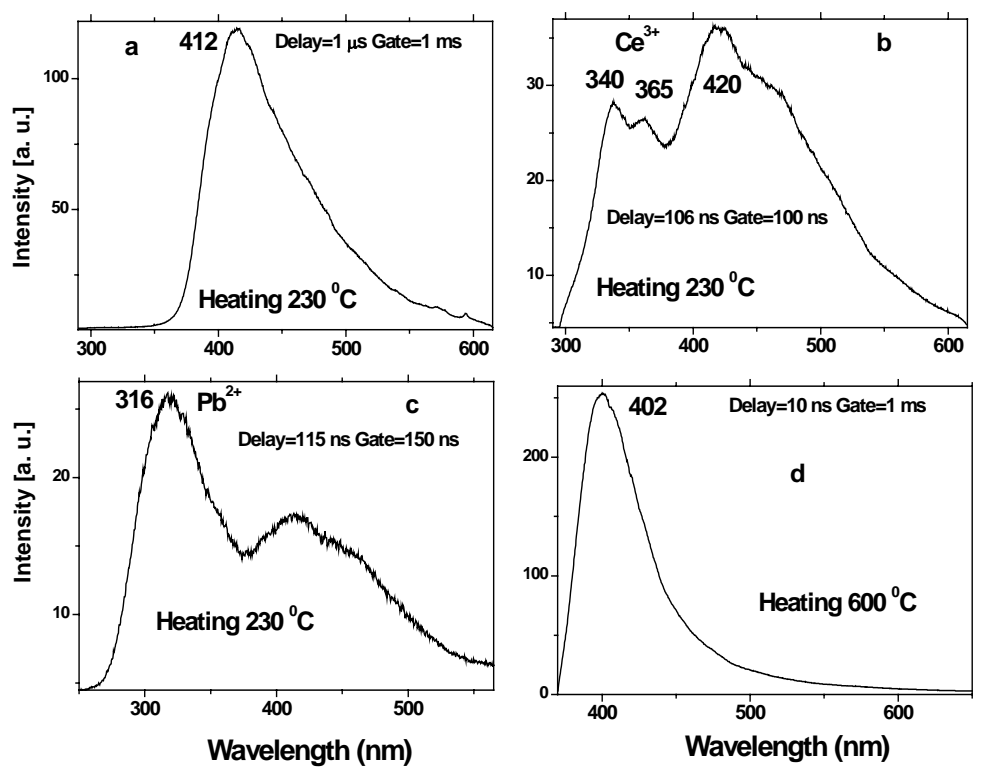

Figure 6.
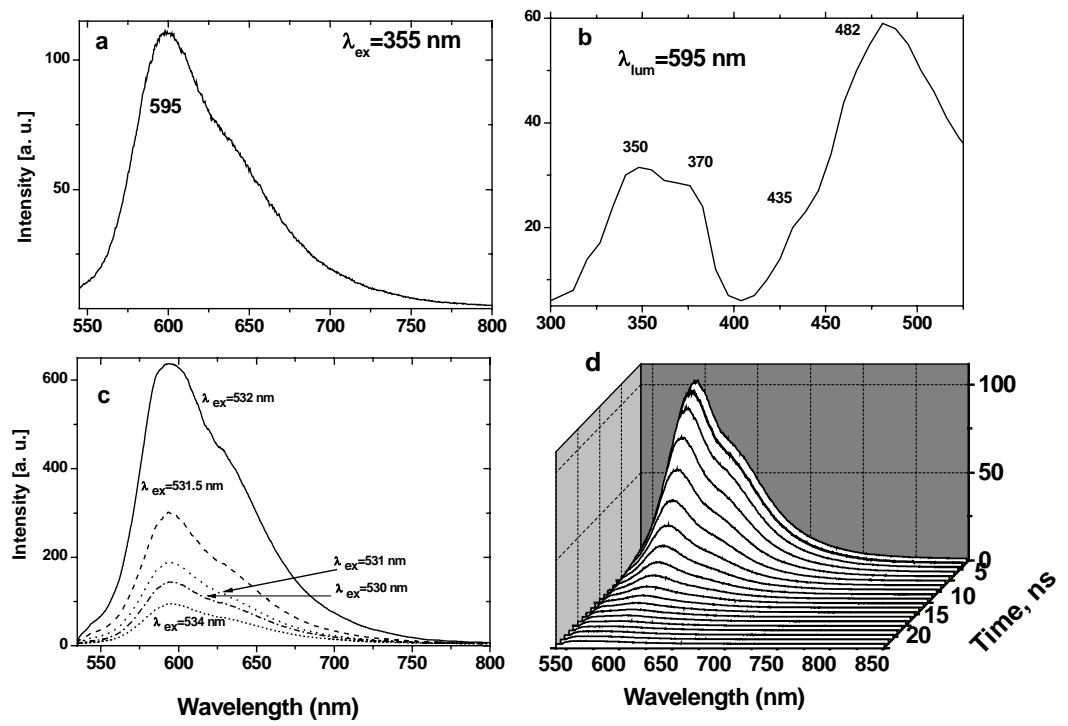

Figure 7. 

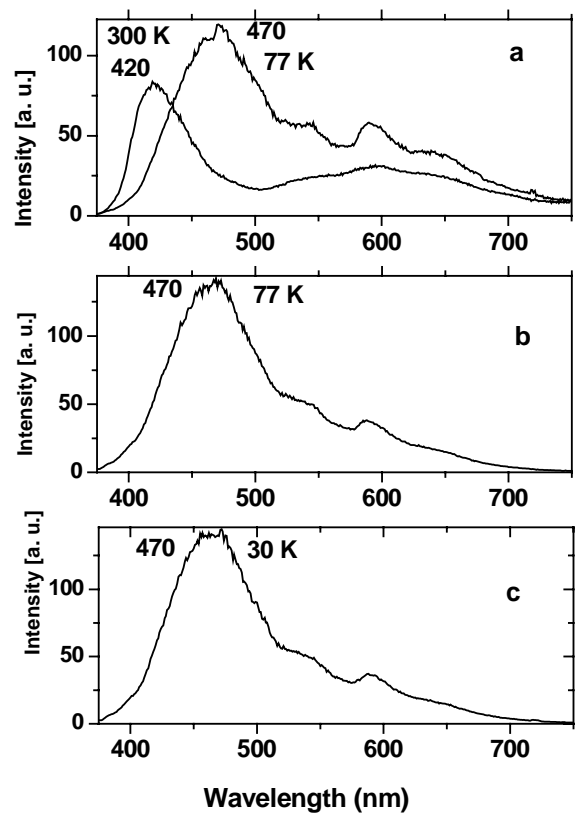

Figure 8.
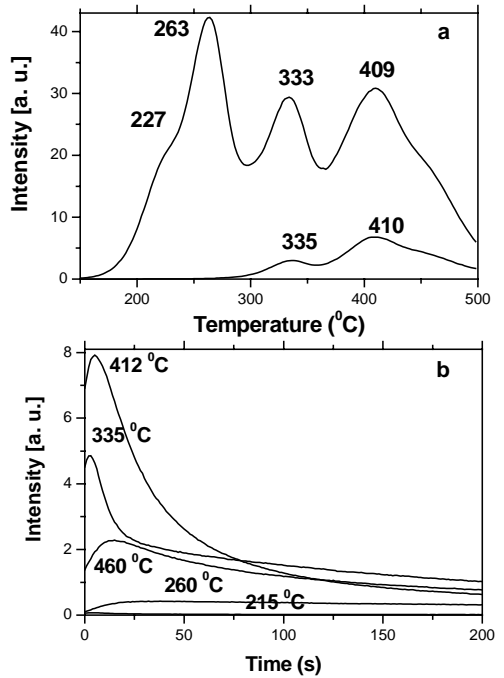

Figure 9. 


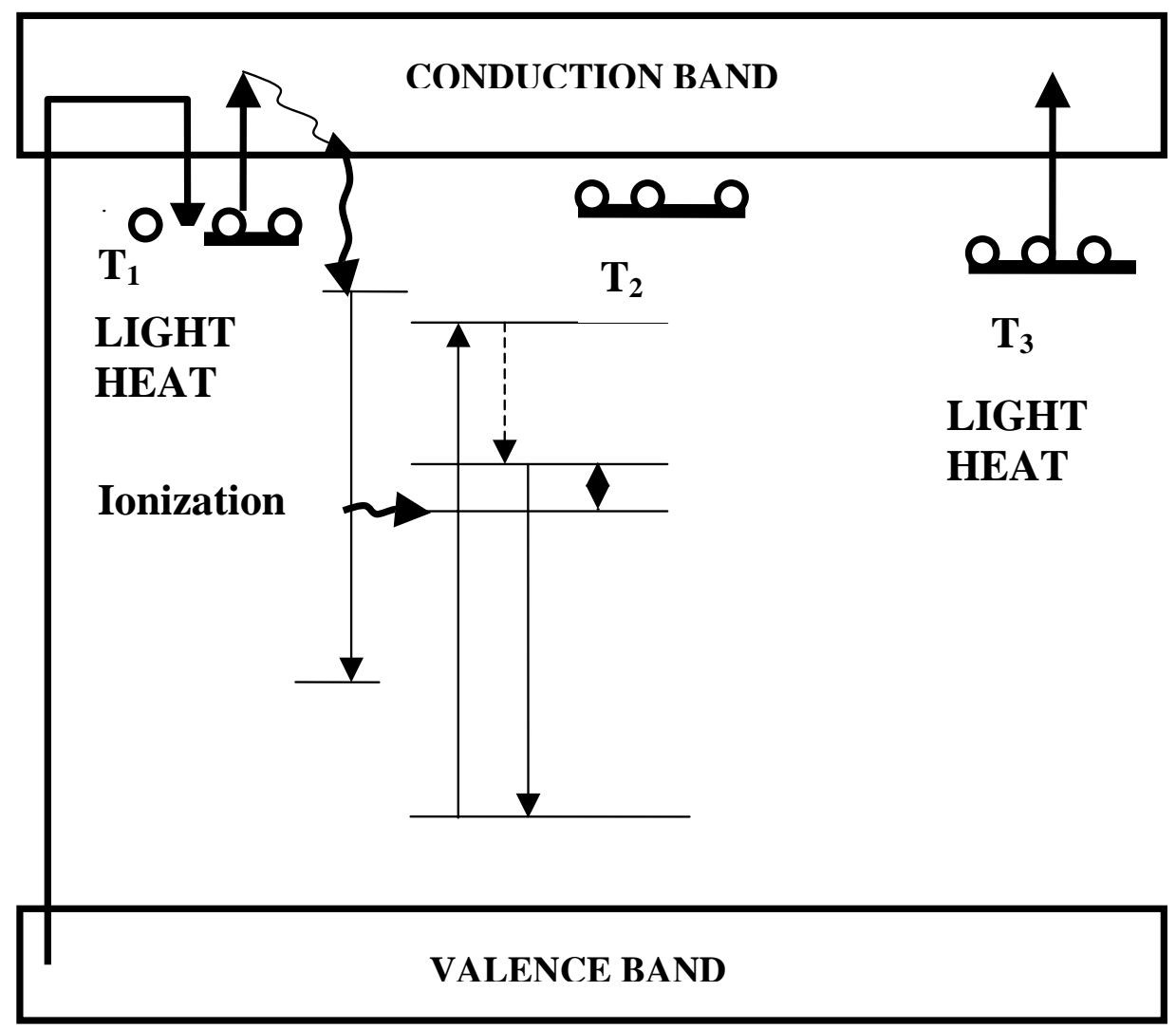

Figure 10. 